\title{
Design Analysis \& Topology Optimization of Passenger Car Disc Brake
}

\author{
Anjali Ashok Shinde ${ }^{(1)}$ \\ ME (Design) Mechanical Engineering \\ JSPM's - R.S. College of Engineering, \\ Pune, Maharashtra
}

\author{
Prof. Shailesh S Pimpale (2) \\ Mechanical Engineer Department \\ JSPM's - R.S. College of Engineering, \\ Pune, Maharashtra
}

\author{
Dr. Subim N. Khan ${ }^{(3)}$ \\ Mechanical Engineering Department \\ JSPM's - R.S. College of Engineering, \\ Pune, Maharashtra
}

\begin{abstract}
The disk brake may be a device for slowing or stopping the rotation of a wheel. Generally repetitive braking system of the automobile cars results in heat generation during each braking event. The brake disc brake 3D model prepared by CATIA software. Finite Element modal analysis of automobile 4 wheeler disc brake is performed to determine mode shapes and natural frequencies and also static analysis is performed to obtain optimized model from topology optimization technique from ANSYS 19 software. Hence, experimental testing using FFT analyzer technique (impact hammer and accelerometer) is performed to determine mode shapes and natural frequency and comparison of results with numerical results.
\end{abstract}

Keyword - Disc Brake, Topology Optimization, FFT Analyzer.

\section{INTRODUCTION}

The racing fans involved will surely know the importance of good brakes not just for safety but also for staying competitive. The disk brake may be a device for slowing or stopping the rotation of a wheel. A brake disc usually made from forged iron or ceramic composites includes carbon, Kevlar and silica, is connected to the wheel and therefore the axle, to prevent the wheel. A friction brake generates frictional forces as two or more surfaces rub against one another, to scale back movement. Based on the planning configurations, vehicle friction brakes are often grouped into drum and disc brakes. The main component of the braking system is the disk brake. Its performance directly affects the driving safety of the vehicle. When the vehicle is braking, the excitation frequency is close to the natural frequency of the brake disk, which will cause resonance, generate severe vibration \& noise \& affect ride comfort. Therefore, it is necessary to analyses modal characteristics of disk brake. TATA Sumo 800 Lacer car disc brake was taken for experimental study purpose. The brake disc (or rotor) is that the rotating a part of a wheel's disk brake assembly, against which the restraint are applied. The material is usually gray iron, a sort of forged iron. The weight and power of the vehicle determines the necessity for ventilated discs.

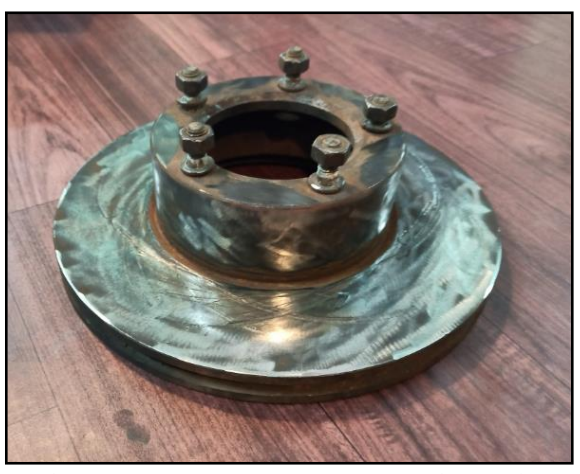

Fig 1.TATA Sumo 800 Lacer Car Disc Brake

\section{II.PROBLEM STATEMENT}

Nowadays, topology optimization technique is used for weight optimization of components which reduces material cost and manufacturing. In present research 4wheeler disc brake is to be studied under FEA to determine the optimum material removal from existing 4wheeler disc brake under existing boundary condition and also determine changes in von misses stress and deformation with tautologized model. Natural frequencies are calculated to determine the nature of mode shapes at respective frequencies

\section{III.METHODOLOGY}

The methodology involves the technology utilized for performing the designing and analysis of the object.

- Design of 4 wheeler disc brake

- Dimension specification

- Analysis of disc brake by ANSYS

- Static structural analysis \& Modal Analysis for mode shape.

- To perform static structural analysis of disc brake under existing boundary condition to obtain deformation and von misses stress and optimized model from topology optimization.

- The best optimized is to be obtained from topology optimization technique and compared to the existing model. 


\section{CAD DESIGN}

Design parameters of TATA Sumo 800 Lacer car

- Disc Diameter

$=260 \mathrm{~mm}$

- Disc Material

$=$ Grey Cast Iron

- Disc Thickness

$=12 \mathrm{~mm}$

- Internal Diameter

$=140 \mathrm{~mm}$

- Internal Thickness

$=50 \mathrm{~mm}$

- Hole Diameter

$=10 \mathrm{~mm}$ Holes

- Pad brake Material

$=$ Asbestos

- Pad Dimension

$=125 \mathrm{~mm} \times 12 \mathrm{~mm}$

Used CATIA software. CATIA is mechanical design software. CATIA users access the highest productivity for specific advanced processes with focused solutions.

- Sketcher

- Part design

- Assembly design

- Wireframe and surface design

- Drafting

- Analysis of disc brake in CATIA

- Meshing Structural Static \& Modal analysis by ANSYS software

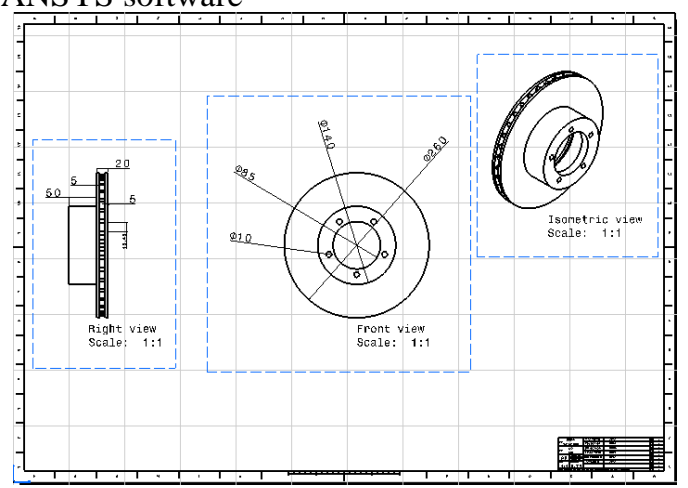

Fig 2 Drafting Of 4 Wheeler Disk Brake

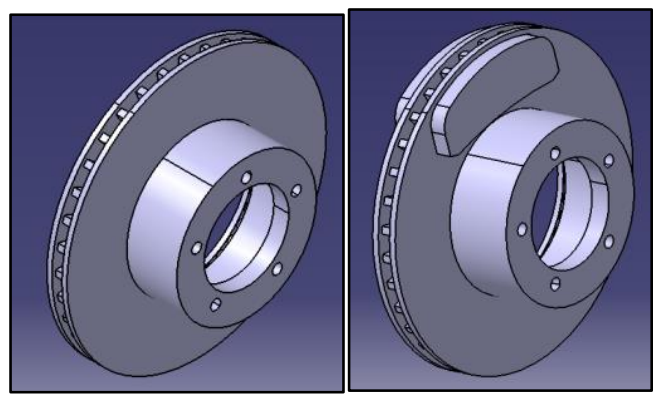

Fig 3 Catia Design of Disc Brake

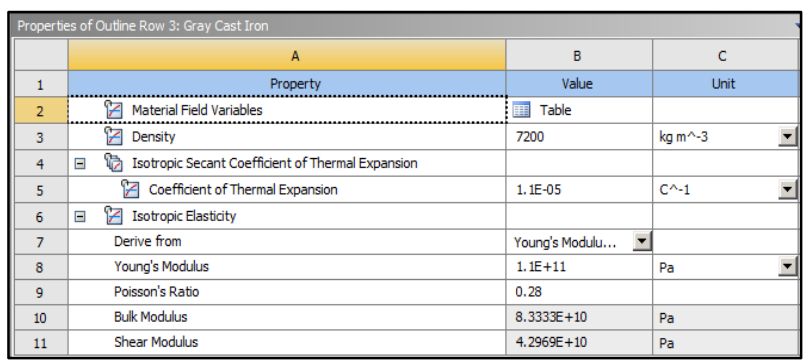

Fig.4 Material Properties of Disc Brake

\section{DESIGN CALCULATION}

Input Parameter for Disc Brake of TATA Sumo 800 Lacer

\begin{tabular}{|l|l|}
\hline \multicolumn{1}{|c|}{ Parameter Name } & \multicolumn{1}{c|}{ Parameter Value (Unit) } \\
\hline Mass of Vehicle & $2625 \mathrm{Kg}$ \\
\hline Speed of Vehicle & $100 \mathrm{~km} / \mathrm{h}=27.7 \mathrm{~m} / \mathrm{s}$ \\
\hline Wheel Diameter & $600 \mathrm{~mm}$ \\
\hline Wheel Base & $2425 \mathrm{~mm}$ \\
\hline
\end{tabular}

Table 1: Basic Parameter of Vehicle

\begin{tabular}{|l|l|}
\hline \multicolumn{1}{|c|}{ Parameter Name } & \multicolumn{1}{c|}{ Grey Cast Iron } \\
\hline Density & $7000 \mathrm{Kg} / \mathrm{m}^{3}$ \\
\hline Yield Tensile Strength & $142 \mathrm{MPa}$ \\
\hline Young Modulus E & $100 \mathrm{GPa}$ \\
\hline Poisson Ratio $v$ & 0.28 \\
\hline Specific Heat, $\mathrm{C}_{\mathrm{p}}$ & $586 \mathrm{~J} / \mathrm{Kg} . \mathrm{K}$ \\
\hline Thermal Conductivity ,K & $54 \mathrm{~W} / \mathrm{m} . \mathrm{K}$ \\
\hline
\end{tabular}

Table 2: Properties of Grey Cast Iron

\begin{tabular}{|l|l|}
\hline \multicolumn{1}{|c|}{ Parameter Name } & \multicolumn{1}{c|}{ Parameter Value } \\
\hline Outer Diameter of Disc & $260 \mathrm{~mm}$ \\
\hline Inner Diameter of Disc & $140 \mathrm{~mm}$ \\
\hline Hole Diameter & $10 \mathrm{~mm}$ \\
\hline Thickness of Disc & $12 \mathrm{~mm}$ \\
\hline Weight of Disc & $6.2 \mathrm{Kg}$ \\
\hline
\end{tabular}

Table 3: Disc Brake Dimensions

Calculation:

a) Kinetic Energy of Vehicle

K.E $=\left(\mathrm{M} \times \mathrm{V}^{2} / 2=(2625 \times 27.72) / 2\right.$

K.E $=1007068.125$ Joule

Where,

K. E - kinetic Energy (J)

M - Mass of vehicle $(\mathrm{Kg})$

$\mathrm{V}$ - Linear velocity of vehicle $(\mathrm{m} / \mathrm{s})$

b) Stopping distance of vehicle

Braking distance of vehicle refers to the distance a vehicle will travel from the point when its brakes are fully applied to when it comes to a complete stop.

The maximum friction force $\mathrm{F}$ [4]

$\mathrm{F}=\mu * \mathrm{M} * \mathrm{~g}$

$=0.7 * 2625 * 9.81$ $\mu=$

0.7 [2]

$\mathrm{F}=18025.8 \mathrm{~N}$

c) Deceleration of the vehicle:

$a=F / M$

$=18025.8 / 2625$

$=6.86 \mathrm{~m} / \mathrm{s} 2$

d) Time taken to stop the vehicle:

$t=V / a$

$=27.7 / 6.86$

$t=4.037 \mathrm{~s} \approx 4 \mathrm{~s}$

e) Distance cover

Maximum speed of vehicle is $27.7 \mathrm{~m} / \mathrm{s}$

So, distance covered by vehicle in 4 second is $=27.7 \times 4$

Stopping distance $(\mathrm{SD})=110.8 \mathrm{~m}$

Now, following is other equation to calculate total stopping distance by considering reaction time of driver is [4]

Total Stopping distance (SD)

$\mathrm{SD}=(V \times$ reactiontime $)+\left(\mathrm{V}_{2} / 2 * \mu * g\right)$ $=(27.7 \times 4)+(27.72 / 2 \times 0.7 \times 9.81)$

$\mathrm{SD}=138.96 \mathrm{~m}$

So, by considering the average stopping distance is $124 \mathrm{~m}$. 


\section{f) Breaking force}

Brake force, also known as Brake Power, is a measure of braking power of a vehicle.

Here following process is given to calculate exact force required to stop vehicle within stopping distance or stopping time. [4]

Tangential braking force: $(B F)$

$(B F) t=K . E /(S D)$ .... (S D - stopping

distance)

$$
=1007068.125 / 124
$$

$(B F) t=8121.51 \mathrm{~N}$

Tangential force on each wheel $F t$

$$
\begin{aligned}
F t & =(B F) / 4 \quad \ldots . .(4 \text { indicate force on each wheel }) \\
& =8121.51 / 4 \\
= & 2030.3 \mathrm{~N}
\end{aligned}
$$

Braking torque on wheel $T w$

$$
\begin{aligned}
T w & =F t \times R \\
& =2030 \times 0.300 \\
= & 609 \mathrm{~N} . \mathrm{m}
\end{aligned}
$$

Where, $\mathrm{R}$ - Radius of the tyre (m)

Effective Rotor radius $\mathrm{Re}$

$\mathrm{Re}=($ Rotor diameter/2) $-($ caliper piston diameter/ 2$)$

$\operatorname{Re}=(260 / 2)-(44 / 2) \quad \ldots($ Rotor diameter $-260 \mathrm{~mm})$

$\mathrm{Re}=103 \mathrm{~mm}=0.103 \mathrm{~m}$

Here, caliper piston diameter is $44 \mathrm{~mm}$.

\section{g) Braking torque on disc $\mathbf{T b}$}

$\mathrm{Tb}=\mathrm{Tw} \times \mathrm{R} / \mathrm{r}$

$$
=609 \times 250 / 125
$$

$\mathrm{mm})$

$\mathrm{Tb}=1218 \mathrm{~N} . \mathrm{m}$

\section{h) Clamping force $\mathbf{C}$ \\ $\mathrm{C}=\mathrm{Tb} / 2 \times \mu \times R e$ \\ $=1218 / 2 \times 0.5 \times 0.103$}

$\mathrm{C}=11825 \mathrm{~N}$

Pressure applied by clamp force on pad = clamping force $/$ area of pad

$$
\left.=11825 / 5145.6 \text { (Area of pad }-5145 \mathrm{~mm}^{2}\right)
$$$$
=2.29 \mathrm{MPa}
$$

\begin{tabular}{|c|c|c|c|c|}
\hline \multicolumn{5}{|c|}{ Properties of Outine Row 3: Gray Cast Iron } \\
\hline & A & B & c & \\
\hline 1 & Property & Value & ur & \\
\hline 2 & T. Material Field Variables & Table & & \\
\hline 3 & 田 Density & 7200 & $\mathrm{~kg} \mathrm{~m} \wedge-3^{\wedge} \mathrm{ln}$ & $\nabla$ \\
\hline 4 & 曰谄 Isotropic Secant Coefficient of Thermal Expansion & & & \\
\hline 5 & Coefficient of Thermal Expansion & 1.11E-05 & $c^{\wedge}-1$ & $\nabla$ \\
\hline 6 & 曰 Z Isotropic Elasticity & & & \\
\hline 7 & Derive from & Young's Modulu... $\quad \mp$ & & \\
\hline 8 & Young's Modulus & 1. $1 E+11$ & $\mathrm{~Pa}$ & $\rightarrow$ \\
\hline 9 & Poisson's Ratio & 0.28 & & \\
\hline 10 & Bulk Modulus & $8.3333 E+10$ & $\mathrm{~Pa}$ & \\
\hline 11 & Shear Modulus & $4.2969 \mathrm{E}+10$ & $\mathrm{~Pa}$ & \\
\hline
\end{tabular}

\section{VI.ANALYSIS}

TATA Sumo 800 Lacer car disc brake is taken for analysis.

After designing disc brake rotors in CATIA V5 the profiles is imported to ANSYS Workbench for further analysis such as Static structural analysis, and Modal analysis.

\section{Material Selection for Disc Brake - Grey Cast Iron}

Fig.5 Engineering Material Properties in ANSYS

\section{- Geometry of Existing Disc Brake}

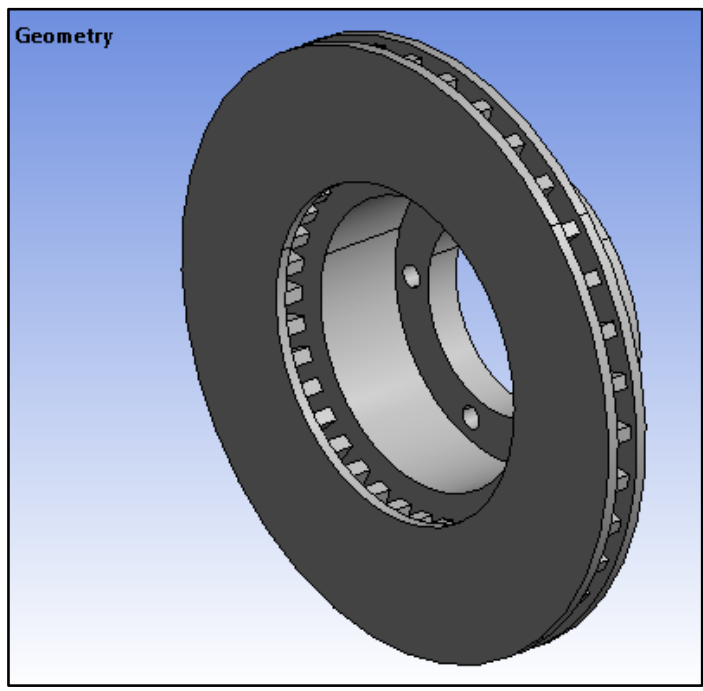

Fig. 6 Geometry of Disc Brake Imported In ANSYS

\section{- Meshing}

Meshing done by ANSYS software to reduced degree of freedom from Infinite to finite with the help of discretization or meshing (Nodes \& Elements)

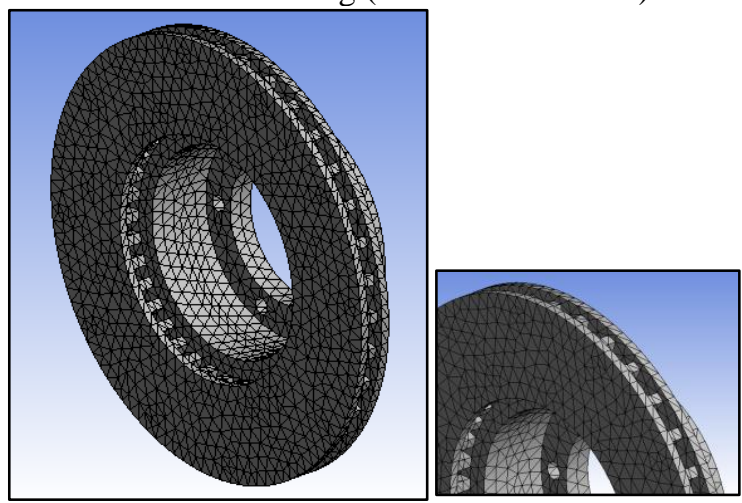

\begin{tabular}{|l|l|}
\hline Statistics \\
\hline$\square$ Nodes & 32313 \\
\hline$\square$ Elements & 16880 \\
\hline
\end{tabular}

Fig. 7 Details of meshing

- Boundary Conditions

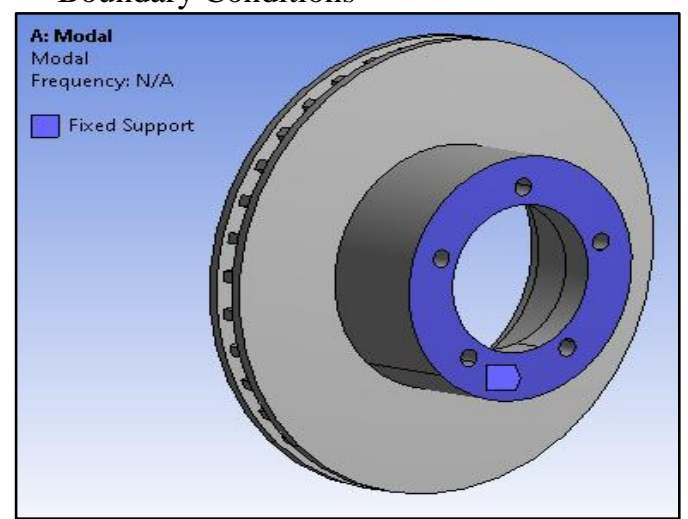

Fig. 8: Boundary Conditions for Disc Brake-MA 
Disc brake is fixed at one end to determine the mode shape and natural frequency.

\section{- Modal Analysis:}

Modal analysis may be a technique to review the dynamic characteristics of a structure under vibrational excitation. Natural frequencies, mode shapes and mode vectors of a structure may be determined using modal analysis.

\section{Different Mode Shapes:}

The modal frequencies of the first five steps and modal shapes of each order shown in below figures:-

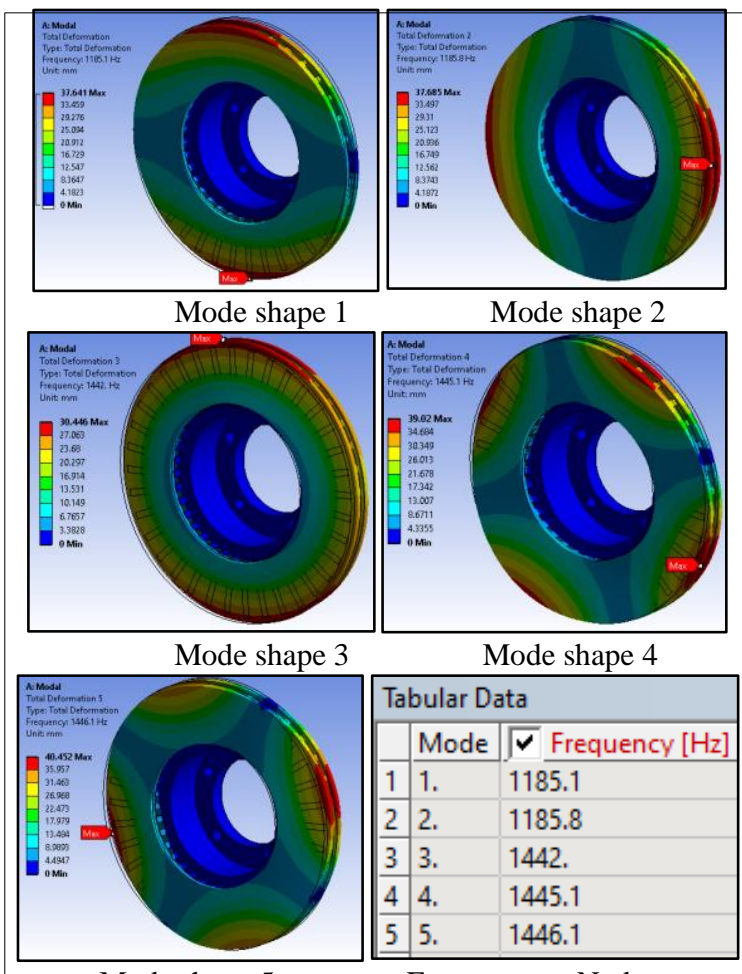

Mode shape 5

Frequency at Nodes

Fig.9 Different Mode Shapes

In above figures different mode shapes are plotted with respective natural frequency so, it is observed the mode shape pattern also change with respective frequency so maximum frequency is observed around $1446 \mathrm{~N}$.

\section{- Static Structural Analysis}

Consider Velocity of Vehicle (V) $=80 \mathrm{~km} / \mathrm{hr}=22.22 \mathrm{~m} / \mathrm{s}$

Where,

V-Velocity of Vehicle

Diameter of Disc brake $(\mathrm{d})=0.26 \mathrm{~m}$

Radius of Disc Brake $(r)=0.13 \mathrm{~m}$

$\mathrm{V}=\mathrm{r} \times \omega$ $(\omega-$ Angular

velocity)

$22.22=0.13 \times \omega$

$\omega=170 \mathrm{rad} / \mathrm{s}$ [4]
In above analytical calculation (A) pressure acting on pad is calculated as $2.29 \mathrm{MPa}$ but design is for maximum condition so standard equation to calculate pressure on pad is given below

From paper mentioned standard equation is $\mathrm{P}(t)=4 \times 10^{6} \cdot\left(1-e^{-\frac{20 t}{2214}}\right)$

$\omega(t)=69.44-22.32 \cdot\left(\mathrm{t}+\frac{3.274}{20} e^{\frac{-20 t}{3224}}-\frac{3.274}{20}\right)$

So, pressure on rubber pad is $4 \mathrm{MPa}$ on both sides are applied.

So, we have $4 \mathrm{MPa}$ and $2.29 \mathrm{MPa}$ as per design. It is beneficial to use $4 \mathrm{MPa}$ as design should sustain extreme pressure due to fluctuation of motion on disc brake.

\section{- Boundary Condition:}
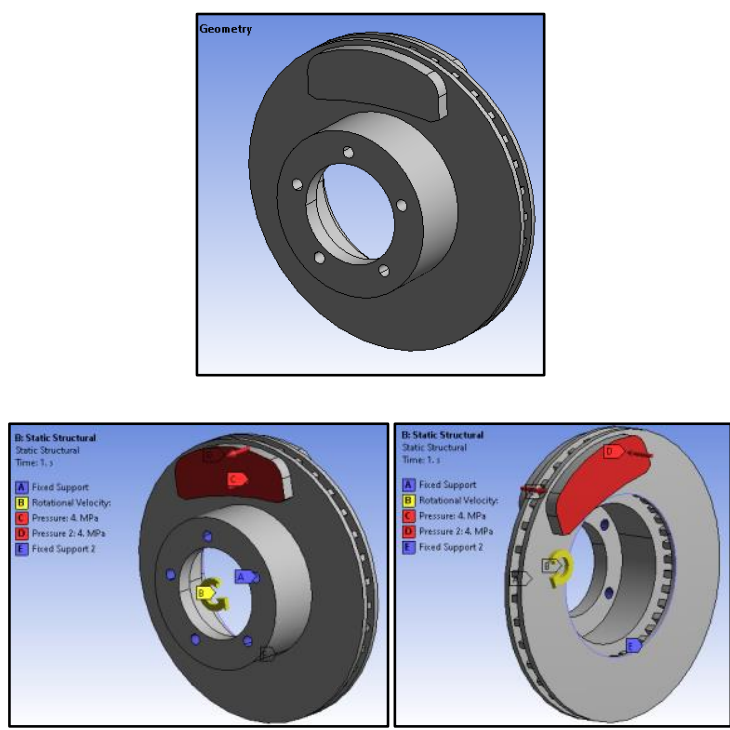

Fig.10 Details of Boundary Conditions-SA

* In boundary condition following are forces, pressure is mentioned.

* Fixed support is applied along circular bolt holes and across edges as per existing situation.

* Pressure of $4 \mathrm{MPa}$ as per calculated analytically is applied on both surface of caliper pad as shown in red region.

* Rotational velocity of $170 \mathrm{rad} / \mathrm{s}=80 \mathrm{~km} / \mathrm{h}$ is applied indicated in yellow region.

\section{- Total Deformation Results}

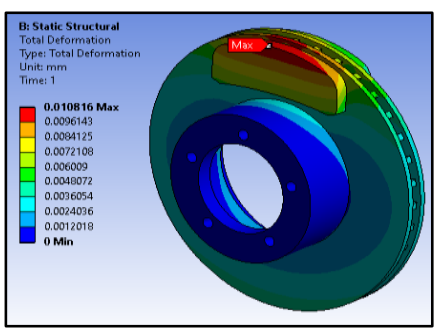

Fig.11 Total Deformation Results 
It is observed that maximum deformation is $0.0108 \mathrm{~mm}$.

\section{- Equivalent Stress Results}

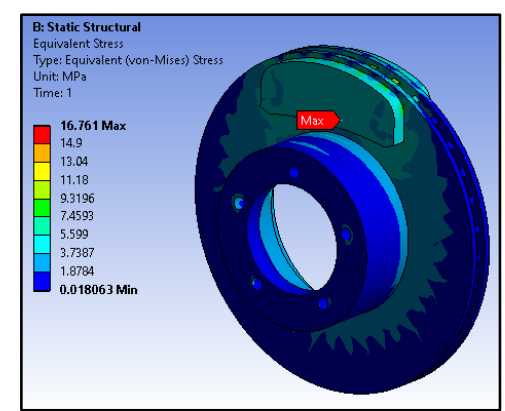

Fig. 12Equivalent Stress Results

Maximum stress observed is $16 \mathrm{MPa}$

\section{VII.TOPOLOGY OPTIMIZATION}

Topology optimization could also be a mathematical approach that optimizes material layout within a given design area, for a given set of loads and boundary conditions such the resulting layout meets a prescribed set of performance targets.

Basic Theory

There are three types of structure optimization,

- Size optimization

- shape optimization

- Topology optimization

Three optimization ways in which correspond to the three stages of the merchandise design methodology, significantly the detailed design, basic design and conceptual design. Size optimization keeps the structural form and topology structure invariant, to optimize the varied parameters of structure, like thickness, section size of beam, materials properties; shape optimization maintains the topology structure, to vary the boundary of structure and form, explore for the foremost applicable structure boundary scenario and shape; topology optimization is to hunt out the foremost effective path of materials distribution throughout never-ending domain that meet the displacement and stress conditions in structure, produce a specific performance optimum. Thus, compared to size and shape optimization, topology optimization with more freedom degree and bigger design area, its greatest feature is below unsure structural form, keep with the well-known condition and a given load to work out a budget structure, every for the abstract sort of recent product and improvement design for existing product, it is the foremost promising side of structural optimization. For continuous structure topology optimization, there are some mature ways like: uniform technique, evolutionary structural optimization technique, variable density technique etc. Uniform technique introduced cell structure of micro structure (unit cell) at intervals the weather of the structure, each unit has three forms, significantly non-material voids $($ size $=1)$, isotropic-material entity medium $($ size $=0)$ and orthotropic-material opening-hole medium $(0<$ size $<1)$. whereby the distribution of every form are able to describe the shape of topology and conjointly the shape of structure; evolutionary structural optimization technique believe that stress in any elements of the structure should beneath the identical level in a perfect structure thus you will be able to delete the fabric artificially.

Thus bit by bit remove material that in a very low stress state, then delete the update rate, thus optimized structure becomes more uniform.

Variable density technique is employed to conduct optimization throughout this paper.

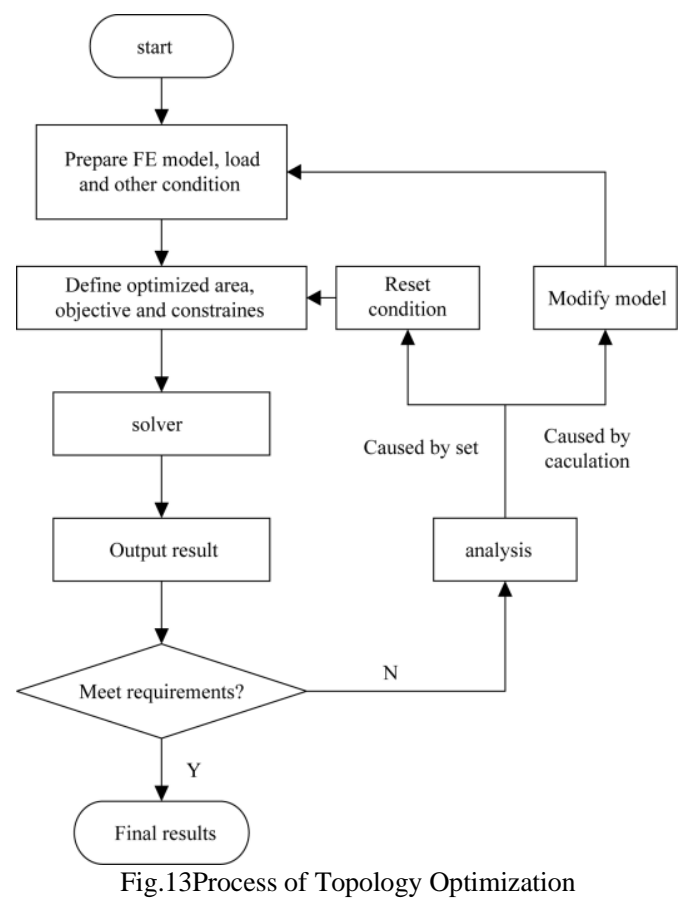

- Boundary Condition

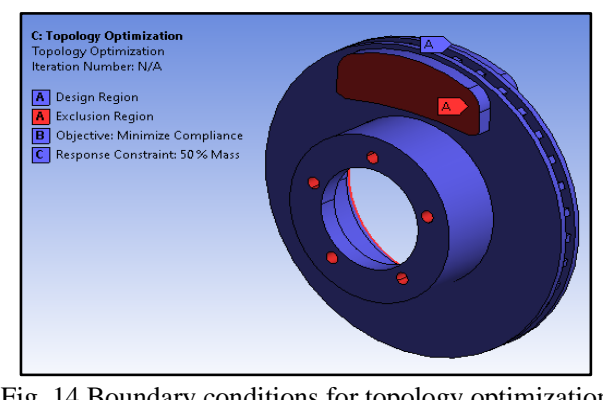

In boundary condition of topology optimization exclusion region are boundary condition applied in static structural analysis these are excluded.

\section{- $\quad$ Equivalent Stress}

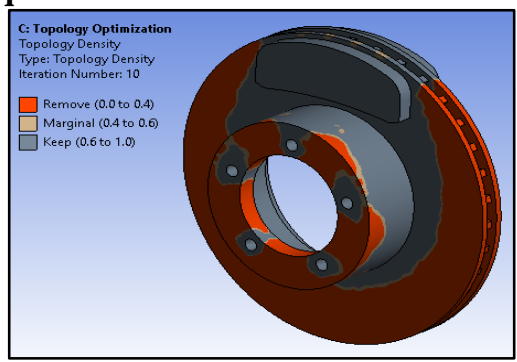




\begin{tabular}{|l|l|}
\hline$\square$ Original Mass & $6.2865 \mathrm{~kg}$ \\
\hline$\square$ Final Mass & $3.4915 \mathrm{~kg}$ \\
\hline$\square$ Percent Mass of Original & 55.539 \\
\hline
\end{tabular}

Fig. 15 Topology Optimization Results

\section{EXPERIMENTAL TESTING}

The experimental validation operation is finished by using FFT

Operation testing (Fast Fourier Transform) analyzer. The FFT spectrum analyzer samples the input, computes the magnitude of its sine and cosine components, and displays the spectrum of these measured frequency components. The advantage of this system is its speed. Because System operation FFT spectrum analyzers measure all frequency components at identical time, the technique offers the likelihood of being persistently faster than traditional analog spectrum analyzers. This analysis will be expressed as a series operation. The fast Fourier transform could be a method of operation mathematical method for transforming a function of your time into a function of frequency. Sometimes it's described as system transforming from the time domain to the frequency domain. it's very useful for all method analysis of time-dependent.

\section{FFT analysis}

FFT is one main property in any sequence getting used generally. To find this property of FFT for any given sequence, many transforms are being employed. the most important issues to be noticed find this property are the time and memory management. Comparison is finished between the 2 algorithms with relevance the memory and time managements and therefore the better one is pointed. Comparison is between the two algorithms written, considering the time and memory because the sole main constraints. Time taken by the 2 transforms find the basic frequency is taken. At the identical time the memory consumed while using the 2 algorithms is additionally checked. Supported these aspects it's decided which algorithm is to be used for better results.

\section{SUMMARY}

* Modal analysis of hydraulic brake is performed to get different mode shapes and natural frequency of existing 4-wheeler hydraulic brake.

* Static structural analysis of hydraulic brake is performed to see deformation and equivalent stress. It's observed around maximum deformation is $0.0108 \mathrm{~mm}$ and equivalent stress is $16.76 \mathrm{MPa}$.

* It's concluded that the region indicated in the pit in topology optimization provides information regarding removal of material from that area it's about $55.53 \%$ to original mass.

\section{REFERENCES}

[1] Transient temperature field of ventilated disc brake under the condition of hard by Numerical and experimental analysis of Qifei Jian, Yan Shui

[2] X Huang, YXie ,Evoltionary Topology Optimization of Continuum Structure,Wiley \& Sons Ltd. 2008

[3] Dynamic behaviors of a wedge disc brake, Khaled R.M. Mahmoud, M. Mourad a, A. Bin Mahfouz c,

[4] Mit Patel ,Mansi Raval ,Design of Disc Brake's Rotor, IJEDR volume 4, Issues 4 ISSN 2321-9939, @ 2016

[5] Design optimization of passenger car front brake disc for improvement in thermal behavior, weight \& Cost reduction, $\mathrm{Mr}$. Prashant Patel, Prof. M.A.Mohite

[6] Structural optimization, thermal and vibration analysis of two wheeler disc brake rotor Mr. Pravin n. Jawarikar, Dr. Subim n. Khan, Mr. Balaji . Kshirsagar. 